\title{
Leveraging Micro-Level Building Information Modeling for Managing Sustainable Design: United Kingdom Experience
}

\author{
Zhen Liu $\mathbb{D}^{\mathrm{D}},{ }^{1}$ Yifang Wang $\mathbb{D}^{2},{ }^{2}$ Mohamed Osmani, ${ }^{3}$ and Peter Demian ${ }^{3}$ \\ ${ }^{1}$ School of Design, South China University of Technology, Guangzhou 510006, China \\ ${ }^{2}$ School of Art and Design, Guangdong Industry Polytechnic, Guangzhou 510300, China \\ ${ }^{3}$ School of Architecture, Building and Civil Engineering, Loughborough University, Loughborough LE11 3TT, UK
}

Correspondence should be addressed to Yifang Wang; evawangyf@hotmail.com

Received 4 October 2019; Accepted 20 May 2020; Published 13 June 2020

Academic Editor: Giosuè Boscato

Copyright (C) 2020 Zhen Liu et al. This is an open access article distributed under the Creative Commons Attribution License, which permits unrestricted use, distribution, and reproduction in any medium, provided the original work is properly cited.

\begin{abstract}
Although the literature revealed the challenges and drivers to implement Building Information Modeling (BIM) in the building design industry in general, to date, there are few established methods and processes to overcome challenges of BIM adoption in building design, especially in sustainable building design for managing the project. At the present, BIM adoption in building design at micro level, that is, the level of architects, mainly focuses on barriers with little attention to method and the process of implementing BIM. Moreover, there is lack of a robust research method, that is, mixed method, to systematically investigate the process of implementing micro-level BIM in building design, which is related to the factors, such as challenges and drivers to the challenges of BIM adoption. Furthermore, several studies have looked into micro-level BIM adoption in architecture firms, but few of them focused on sustainable design. This emphasizes a need to investigate and explore micro-level BIM implementation challenges alongside its drivers in building design and present methods and processes generated from architects' perspectives to address the challenges during sustainable design for the project management, which is the aim of this paper. The research investigation was through a questionnaire that is followed by interviews with the leading architectural firms within the UK. The research reported in this paper is to present a clear view of challenges to micro-level BIM adoption and a framework/road-map to address the key challenges in managing sustainable building design projects, which are related to cultural resistance and culture change, top-down management support, current key challenges and drivers, and client and project managers' interests. The methods and processes that enhanced the framework can be instantly adopted for building design and for architectural companies including small- and medium-sized enterprises (SMEs).
\end{abstract}

\section{Introduction}

The building industry has been called to decrease project lifecycle cost, increase productivity, efficiency, quality, and sustainability, and reduce project delivery time by adopting established techniques, such as Building Information Modeling (BIM). BIM offers the potential to deliver many benefits [1]. BIM simulates building design projects in a virtual environment, in which a building and the processes of design, construction, and operation are digitally and accurately modelled as a BIM model shared by all stakeholders. As such, the BIM/common model contains precise geometry and associated data for the whole building design process and activities to use for simulation of the building from design to construction [2]. After construction, the model can be handed over for use in the facility management purposes.

In the UK, the 2011 construction industry strategy [3] has instigated great attention to BIM, with all public projects required to implement BIM as the first stage in the journey towards national BIM adoption. Recently, the UK Construction Strategy 2050 [4] called for all government projects to set targets including a general increased efficiency of delivery, improved sustainability (i.e., by 2050, carbon emissions will be $80 \%$ lower than those in 1990), and $20 \%$ reduction of costs. It is believed that BIM-based emerging techniques can help with building design throughout the project lifecycle stages to achieve these targets. In addition, 
the Royal Institute of British Architects (RIBA), in conjunction with Green Overlay and BIM Overlay, published RIBA Plan of Work 2013 [5] that has task bars for sustainability and information deliverables and provides stepby-step guidance for architects using BIM to design and manage construction projects. Further, building owners are more aware of BIM benefits, including improved efficiency of the design, construction, and operation [6]. Owners are starting to insist that architects and other design professionals adopt BIM [7]. Design is the stage with the biggest influence on the sustainability performance of a project from a building lifecycle perspective [8]. Hence, the architecture profession has been coming under increasing pressure to adopt BIM. However, little effort has been made to date to establish a clear view of challenges of micro-level BIM adoption process to address the key challenges and drivers during design to achieve sustainability. As such, this paper aims to investigate micro-level BIM implementation challenges alongside its drivers in building design and present methods and processes, such as BIM adoption and a framework/road-map generated from architects' perspectives in leading architectural design companies. This would address the project management challenges that arise when sustainability targets need to be incorporated into the design process. Thus, the paper makes an original contribution by targeting sustainable building design at micro level of BIM adoption in architecture firms, focusing on development of method and process for BIM implementation concerning factors, that is, the BIM adoption challenges and drivers, rather than factors and systematically investigating the process of implementing micro-level BIM in building design.

Hence, this paper reviews the literature in BIM adoption level including macro level and micro level, current challenges of the adoption, and main drivers addressing the challenges during design, which is followed by the identification of a gap in the literature to be addressed by this research. A mixed research method is adopted. Moreover, the research results are presented regarding current BIM adoption challenges and drivers and potential methods, that is, BIM adoption and a framework/road-map, for overcoming the key challenges in sustainable building design. Furthermore, the paper discusses the four key findings of the study in micro-level BIM adoption, such as cultural resistance and culture change, top-down management support, current key challenges and drivers, and client and project managers' interests.

\section{Literature Review}

At present, the level of adoption of BIM varies across the continents of the world and the macro and micro levels. As shown in Table 1, the literature of BIM adoption indicates that BIM has been studied in macro level $[9,10]$ and micro level [11-22], where BIM players are from authority, large organization, and industry associations to small- and medium-sized enterprises (SMEs), where large organization concerns facility management for organizational and project contexts [11]. Micro-level BIM adoption in SMEs involves key project stakeholders in building design and project management [16], and the BIM players focus their expertise on construction contractor [17], mechanical contractor [13], estimating contractor [14], public facility agency [15], and designers [18] including engineer, landscape architect, and architect [19-22]. In addition, issues of micro-level BIM adoption have a significant impact on conceptual structures $[9,10]$, while at micro level concerns focus more on barriers to adoption $[12,17,18,21]$ than managing projects [16] in technology, organization, and environment [19], organizational structure [14], organizational and project contexts [11], mechanism [13], process [20], project benefits and occupant value [15], and user behavioral intentions [22]. Further, the study at macro level of BIM adoption uses theory-building and secondary data method [9] for investigation of BIM adoption, while studies at macro level employ number research methods, such as questionnaire $[17-19,21]$, interview $[16,20,22]$, case study $[11,15]$, and focus group [14] and mixed methods including face-to-face interview and follow-up online questionnaire [12] and case study and follow-up interviews [13]. The studies in the field, from 2011 to 2017, specifically focused on Asia $[18,19,21,22]$, Europe [16, 17, 20], North America [11, 13], and Oceania $[12,14]$.

However, currently, there are six key challenges to the adoption of BIM in design, as shown in Table 2, which are related to culture change, collaboration and interoperability, framework and training, project partners, legal and contractual agreements, and project size.

In recent years, legal concerns about ownership, payment rights, risk transfer, standards of care, and compensation for BIM implementation of BIM models have increased [23, 24, 28].

There are five current main drivers during design, which are believed to help with overcoming the challenges driving the use of BIM, namely, client driven [16, 25-27], project manager driven in terms of communication and project management $[16,21,23]$, easy and efficient information retrieval for increasing staff productivity [12, 13, 19, 22], project level implementation in terms of cost efficiency and delivery speed increase $[19,21]$, and construction strategy $[7,18,21,25-27]$.

\section{State of the Art and Research Gaps}

Although the literature revealed the challenges and drivers to the adoption of BIM in AEC industry in general, up to date, there are a few established methods and processes to overcome BIM adoption challenges during building design, especially in sustainable design. As shown in Table 1, at present, BIM adoption in building design at micro level, that is, the architect level, mainly focuses on factors of barriers with little attention to method and process of implementing BIM related to the factors.

Moreover, there is lack of a robust research method, that is, mixed method, to systematically investigate the process of implementing micro-level BIM in building design, which is related to the factors, such as challenges and drivers of the BIM adoption. A number of studies employ a single research 
TABLe 1: Summary of the literature on Building Information Modeling (BIM) adoption in terms of BIM players.

\begin{tabular}{|c|c|c|c|c|c|}
\hline $\begin{array}{l}\text { Building } \\
\text { Information } \\
\text { Modeling (BIM) } \\
\text { adoption level }\end{array}$ & BIM player & BIM adoption issue & Research method & Country of study & Source \\
\hline Macro level & $\begin{array}{l}\text { From authority, large } \\
\text { organization, and industry } \\
\text { associations to small } \\
\text { organizations }\end{array}$ & Conceptual structures & $\begin{array}{l}\text { Theory-building and } \\
\text { secondary data }\end{array}$ & Worldwide & $\begin{array}{l}\text { Succar and } \\
\text { Kassem } \\
{[9,10]}\end{array}$ \\
\hline \multirow{12}{*}{ Micro Level } & A large owner organization & $\begin{array}{l}\text { Organizational and } \\
\text { project contexts in } \\
\text { facility management }\end{array}$ & Case study & Canada & $\begin{array}{c}\text { Cavka et al. } \\
\text { [11] }\end{array}$ \\
\hline & $\begin{array}{l}\text { Small- and medium-sized } \\
\text { enterprises (SMEs) in } \\
\text { construction }\end{array}$ & Factors & $\begin{array}{l}\text { Face-to-face interview } \\
\text { and follow-up online } \\
\text { questionnaire }\end{array}$ & Australia & $\begin{array}{l}\text { Hong et al. } \\
\text { [12] }\end{array}$ \\
\hline & $\begin{array}{c}\text { Mechanical contracting } \\
\text { SMEs }\end{array}$ & A mechanism & $\begin{array}{l}\text { Case study and } \\
\text { semistructured } \\
\text { interviews }\end{array}$ & Canada & $\begin{array}{l}\text { Poirier et al. } \\
\text { [13] }\end{array}$ \\
\hline & Estimating organizations & $\begin{array}{c}\text { Adjustment of } \\
\text { organizational structure }\end{array}$ & Focus group & Australia & Olatunji [14] \\
\hline & Public facility agencies & $\begin{array}{l}\text { Actions' impacts on } \\
\text { project benefits and } \\
\text { occupant value }\end{array}$ & Case studies & Worldwide & $\begin{array}{l}\text { Gurevich } \\
\text { et al. [15] }\end{array}$ \\
\hline & Key project stakeholders & Project management & Interview & $\begin{array}{l}\text { Mediterranean } \\
\text { countries }\end{array}$ & $\begin{array}{l}\text { Travaglini } \\
\text { et al. [16] }\end{array}$ \\
\hline & $\begin{array}{l}\text { Leading construction } \\
\text { contractor }\end{array}$ & Factors of barrier & Online questionnaire & United Kingdom & $\begin{array}{l}\text { Eadie et al. } \\
\text { [17] }\end{array}$ \\
\hline & $\begin{array}{c}\text { Designers (i.e., engineer, } \\
\text { architect, and landscape } \\
\text { architect) }\end{array}$ & Factors of barrier & Questionnaire & $\begin{array}{l}\text { Hong Kong, } \\
\text { China }\end{array}$ & Chan [18] \\
\hline & $\begin{array}{l}\text { Architectural firms (team of } \\
\text { architects) }\end{array}$ & $\begin{array}{l}\text { Technology, } \\
\text { organization, and } \\
\text { environment }\end{array}$ & Questionnaire & India & $\begin{array}{c}\text { Ahuja et al. } \\
\text { [19] }\end{array}$ \\
\hline & Architectural firms & $\begin{array}{c}\text { Process of lean design } \\
\text { practice }\end{array}$ & Face-to-face interviews & United Kingdom & $\begin{array}{c}\text { Arayici et al. } \\
{[20]}\end{array}$ \\
\hline & Architects in Shenzhen city & Factors & Questionnaire & China & $\begin{array}{c}\text { Ding et al. } \\
{[21]}\end{array}$ \\
\hline & Architects & Behavioral intentions & Face-to-face interviews & $\begin{array}{l}\text { Republic of } \\
\text { Korea }\end{array}$ & Son et al. [22] \\
\hline
\end{tabular}

TABLE 2: Summary of the literature on current key challenges of adoption of BIM in design.

\begin{tabular}{|c|c|}
\hline Current key challenges of BIM adoption in design & Source \\
\hline $\begin{array}{l}\text { Overcoming the resistance to change by educating pro } \\
\text { stakeholders to be aware of potential and value of BIM }\end{array}$ & $\begin{array}{l}\text { Cavka et al. [11]; Poirier et al. [13]; Eadie et al. [17]; Son et al. [22]; } \\
\text { Arayici et al. [20] }\end{array}$ \\
\hline $\begin{array}{l}\text { Insufficient standards and protocols between project players in } \\
\text { collaboration, integration, and interoperability }\end{array}$ & $\begin{array}{l}\text { Cavka et al. [11]; Poirier et al. [13]; Olatunji [14]; Eadie et al. [17]; } \\
\text { Chan [18]; Ding et al. [21]; Son et al. [22]; Ghaffarianhoseini et al. [23]; } \\
\text { Bernstein et al. [20]; Howard and Björk [24]; Ku and Taiebat [24] }\end{array}$ \\
\hline $\begin{array}{l}\text { Lack of a framework/ro } \\
\text { and method to implem } \\
\text { understand and adopt } \mathrm{I}\end{array}$ & $\begin{array}{l}\text { Olatunji [14]; Eadie et al. [17]; Chan [18]; Ding et al. [21]; Son et al. } \\
\text { [22]; Ghaffarianhoseini et al. [23] }\end{array}$ \\
\hline and implementation of BIM between project & Eadie et al. [17]; Ding et al. [21]; Ku and Taiebat [24] \\
\hline $\begin{array}{l}\text { Lack of legal/contractual agreements associated with the BIM } \\
\text { model }\end{array}$ & $\begin{array}{l}\text { Poirier et al. [13]; Eadie et al. [17]; Ghaffarianhoseini et al. [23]; Ku } \\
\text { and Taiebat [24] }\end{array}$ \\
\hline $\begin{array}{l}\text { Different project sizes: big projects adopt BIM more easily than } \\
\text { smaller projects }\end{array}$ & Poirier et al. [13]; Cao et al. [25]; Hong et al. [26]; NBS [25-27] \\
\hline
\end{tabular}


method for the investigation, such as questionnaire, interview, case study, or focus group.

Furthermore, there are several studies that looked into micro-level BIM adoption in architecture firms, but few of them focus on sustainable building design. Ahuja et al. [19] looked into perspectives from technology and organization to environment of architectural firms via questionnaire in India for adoption of BIM. Ding et al. [21] surveyed architects by questionnaire in Shenzhen, China, to identify key factors for BIM adoption. Son et al. [22] engaged the Technology Acceptance Model (cite reference) to explore behavioral intentions of architects to adopt BIM via face-toface interviews of architects in the Republic of Korea. Similarly, Arayici et al. [20] specifically developed a process of lean design practice aided by BIM, resulting in sustainability, through face-to-face interviews from an architectural company in the UK.

This highlights a need to explore micro-level BIM implementation challenges and drivers in building design and to present methods and processes generated from architects' perspectives to overcome the challenges during sustainable design for the project management, which this paper focuses on.

\section{Method}

This research uses a mixed research method to investigate BIM adoption drivers and challenges in building design and potential techniques to address the challenges during building design towards sustainability. The quantitative to qualitative data were collected, and then a questionnaire was followed by face-to-face semistructured follow-up interviews. The research selected the top 100 UK leading architectural design firms listed in Building magazine as the sample. The questionnaire explored the drivers for BIM adoption and challenges during design. Fifty participants completed the questionnaire, with 28 architects (Group A participants) adopting BIM for sustainable building design, while 22 architects (Group B participants) had not. Further investigation of potential methods to address the challenges during sustainable design was explored through the followup interviews with 11 questionnaire respondents volunteering to be interviewed to obtain the qualitative data.

\section{Results}

The questionnaire and interview data were used to identify barriers and drivers to micro-level BIM adoption and to propose an adoption process to addresses the challenges.

\subsection{Current Building Information Modeling (BIM) Adoption} Drivers. The architects who responded to the questionnaire were asked to rate the current drivers from 1 to $4(1=$ not an incentive, 2 =low incentive, 3 = significant incentive, and 4 = high incentive) for using BIM in building design including sustainable design.

The results, as shown in Table 3, suggest that current drivers, such as client driven, staff production improvement, construction strategy, and project level implementation, significantly drive the use of BIM by Group A architects who used BIM for sustainable design projects. Interestingly, "project manager driven" appeared as a low incentive. In addition, mean scores of Group A and Group B architects' responses about the drivers of using BIM are not statistically significant at the 0.05 level as shown in Table 4, where all of the Sig. (2-tailed) values are greater than 0.05 .

5.2. Current BIM Adoption Challenges. The questionnaire respondents were asked to rate the current challenges from 1 to 4 ( $1=$ not a challenge, $2=$ low challenge, $3=$ significant challenge, and $4=$ high challenge) to the use of BIM in building design including sustainable design.

The results in Table 4 show that participating architects in Group A who had BIM experience in sustainable design acknowledged current significant challenges to adopt BIM in building design, such as insufficient standards and protocols between project players in collaboration, integration, and interoperability, lack of a framework/road-map for outlining the effective strategy and method to implement BIM and train project stakeholders to understand and adopt BIM, resistance to change, and imbalance adoption and implementation of BIM between project partners and players. The different project sizes had a low effect on BIM implementation. Further, participating architects in Group A and Group B have no statistically significant difference in their rating of current BIM adoption challenges.

\subsection{Potential Methods for Addressing Key BIM Adoption} Challenges in Sustainable Building Design. As discussed above, interoperability, resistance to change, imbalance of adoption and implementation of BIM between project partners and players, and lack of framework/road-map were nominated as significant challenges in BIM adoption during building design by architects who responded to the questionnaire. Hence, 11 architects who implemented BIM for sustainable design and had the interview were asked for their views on addressing those challenges to achieve sustainability by adopting BIM. Interview data were analysed using thematic analysis.

All interviewees emphasized that the first three challenges are associated with technology, communication, and understanding of BIM. Hence, one interviewee explained how to address these challenges, such as early dialogue on the types of technologies used in sustainable design projects, maintaining open communication between all the project partners throughout design process, and clarifying the purpose of BIM adoption in sustainable design projects. The participating architects suggested a number of methods to overcome the three challenges in adopting the micro level of BIM for sustainable design, which are summarized in Figure 1 as a framework/road-map to aid addressing the challenges in a set of BIM training oriented and integrated methods including BIM package and practices for addressing interoperability challenge, as well as culture change, BIM project show case, and regulation and legislation for addressing challenges such as resistance to change and imbalance of adoption and implementation of BIM 


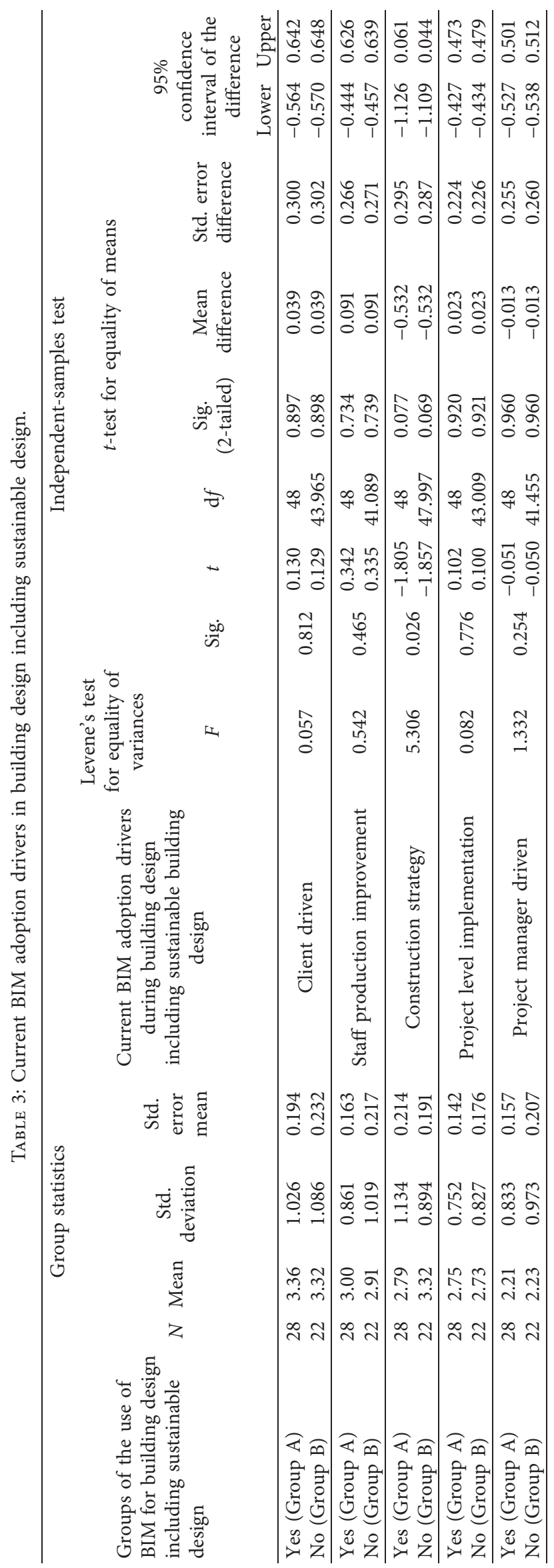




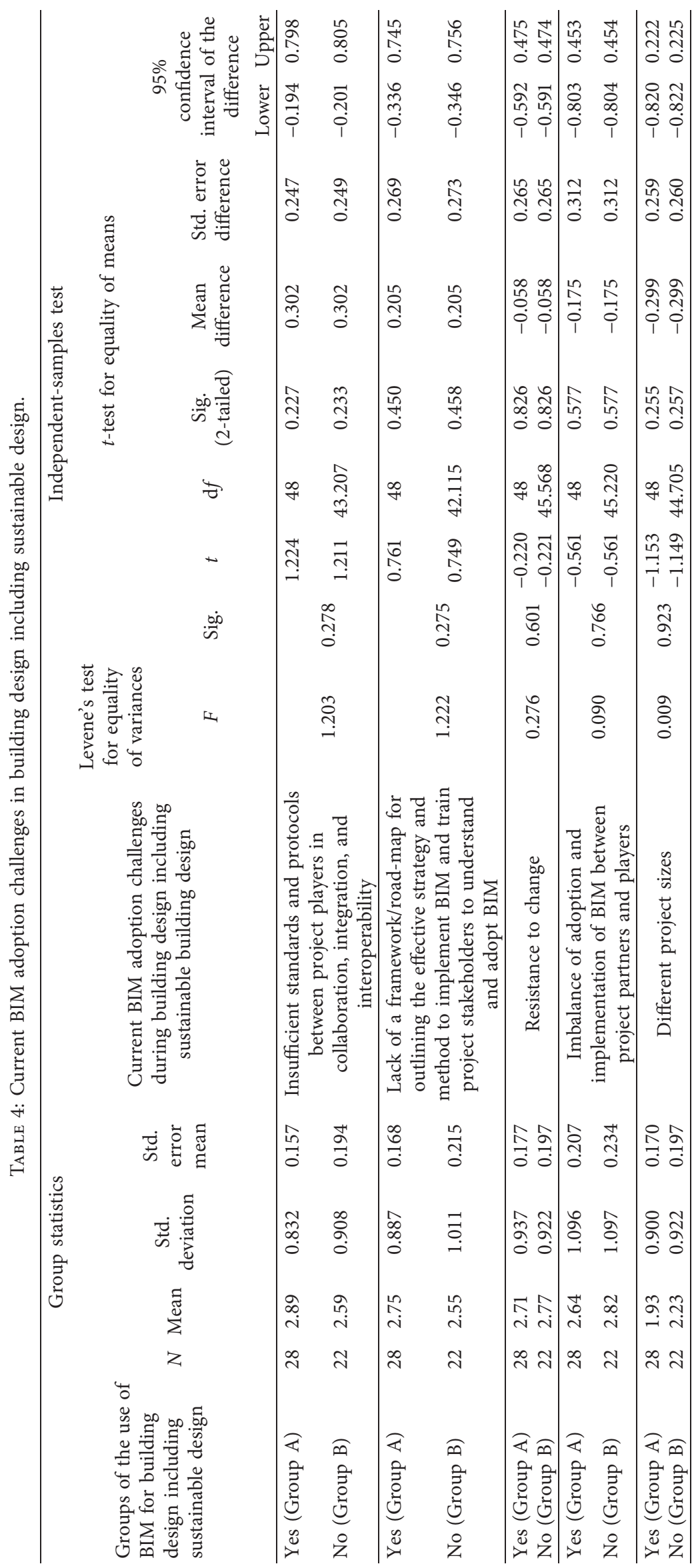




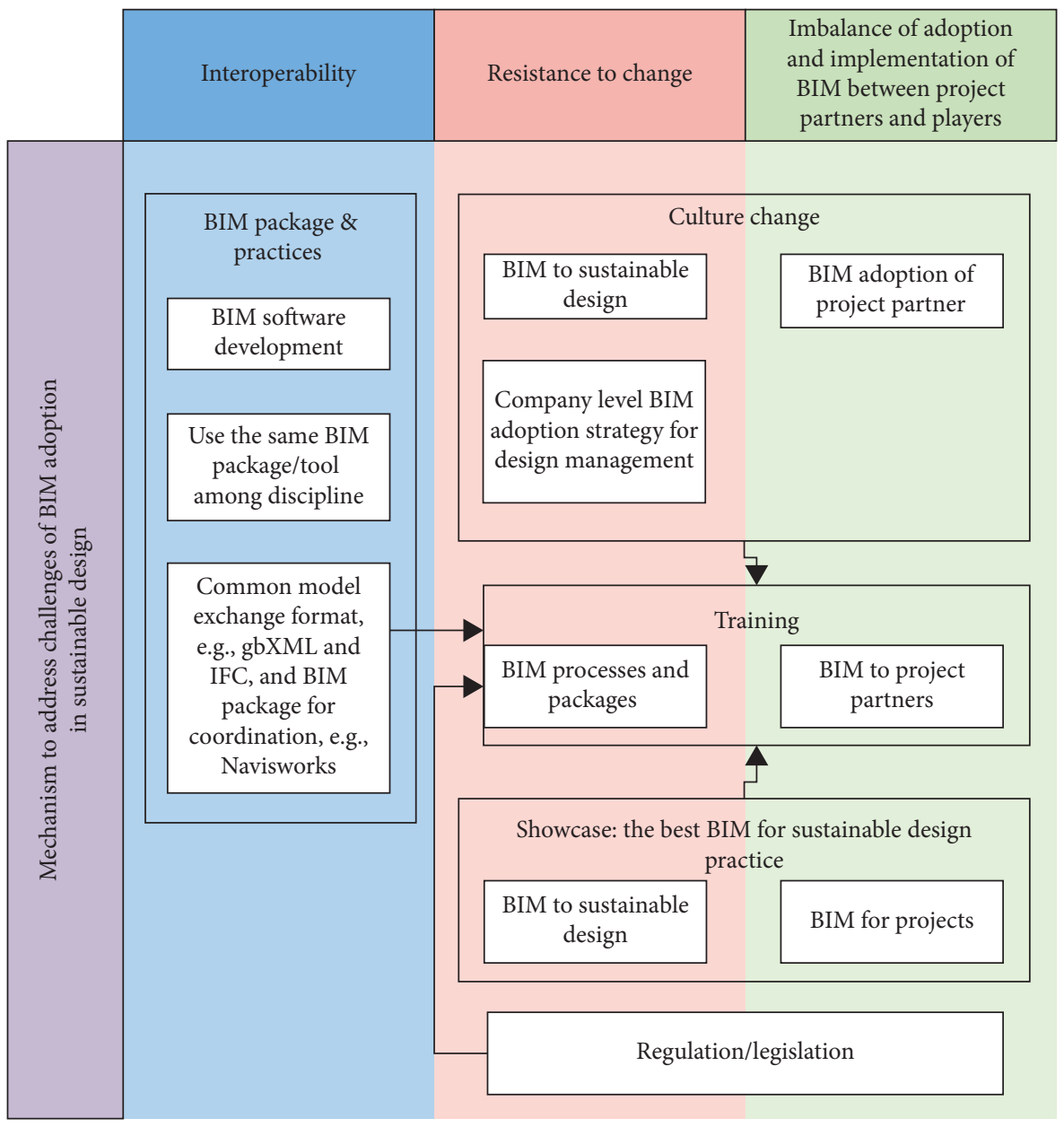

FIGURE 1: A micro level of BIM adoption framework embedding methods that can overcome key BIM adoption challenges in managing sustainable building design projects (devised by the authors based on interviewees' responses).

between project partners and players. The analysis is based on the proposed key elements and their interrelated relationships, which are discussed in following paragraphs.

Interviewees generally believed that interoperability issues in sustainable design are related to translation and communication between different BIM software platforms, primarily for sustainability performance simulation and analysis. 6 of 11 interviewees stressed that this problem can be solved by further developing the compatibility of BIM software packages, so that information can be easily shared, or design team members and project members use the same software package. It will improve sustainable design information sharing capability via enhancement of communication and modeling between various BIM software packages. Moreover, 7 of 11 interviewees suggested adopting a standard model format, that is, gbXML (Green Building eXtensible Markup Language) and IFC (the Industry Foundation Classes), to assist in the interoperability of model exchange issues in the sustainable design process, which is shown in Figure 1. This can assist training in BIM to overcome the resistance to change and the underutilization of BIM by other project partners and players. As one interviewee highlighted, although IFC is the most commonly used model exchange format for all parties to share information, it tends to lose information, such as semantic parameter information that constraints associated with $3 \mathrm{D}$ model elements. Further, one interviewee indicated that BIM packages for model coordination and clash detection, such as Navisworks, can improve interoperability by allowing BIM users to merge models from different disciplines, which reduces construction waste resulting in achieving more sustainability. However, 4 of 11 interviewed architects argued that interoperability should not be a problem, since project members are always able to find a way to address issues of file formats.

Based on the view of interviewees, the challenges faced by BIM adoption can be alleviated, which are resistance to change and the imbalance of adoption and implementation of BIM between project partners and players. This also can be improved by implementing design culture change, training, demonstrating the best sustainable design practices using BIM, and BIM-related regulation and legislation, as summarized in Figure 1.

7 of 11 interviewed architects believed that the challenge of resistance to BIM can be addressed by providing training to the project partners and players on using BIM packages 
and processes for sustainable design. They further stated that, by providing training project partners, they will ultimately promote the BIM adoption at the project level, where the mechanism is illustrated in Figure 1. As one architect suggested, educating project partners and players will lead to full collaborative participation and understand all the benefits of BIM's process to promote sustainable design. In addition, four of them emphasized that issues of working culture play a key role in the resistance. One architect made it clear that, generally, architects think that BIM packages take over their roles to control design and promote sustainable options by providing suggestions to limit their artistic design, which they dislike. However, another architect argued that cultural change in BIM to facilitate design and sustainability should be addressed before training, because architects cannot be trained if "they do not believe in BIM." The cultural change in BIM adoption that promotes sustainable design should be focused on a design management change first at the organizational level and followed by a change in implementation of BIM packages at the technical level. One interviewee stressed that it is clearer that more seniors need to encourage designers to adopt BIM from a top-down flow, which will really change the design management and allow them to work as much as possible through BIM in an easy method.

Further, 4 of 11 participating architects believed that, for architects and project partners and players, the legislation/ regulation is the driving force behind BIM adoption for sustainable design. Interestingly, two interviewees took a view that digitally publishing and sharing design documents can enable design project partners to implement BIM for better communication and coordination, as BIM will help with leading to multidisciplinary design and practice that enables it to be implemented for sustainable design more effectively and efficiently. However, one of the responding architects argued that although BIM may not be adopted by project partners and players, this should not be a challenge for architects to use BIM in sustainable design, since the architects can actually be assisted and benefit from implementing the micro-level BIM.

\section{Discussion}

The process of adopting BIM may be slower than what industry and government agencies imagine, because BIM is inclusive and appeals to all project stakeholders [23]. There are four key findings of this study of micro-level BIM adoption, which are related to cultural resistance and culture change, top-down management support, current key challenges and drivers, and client and project managers' interests.

6.1. Cultural Resistance and Culture Change. To educate project stakeholders for understanding the BIM potential and its value to address the resistance to change, in short "cultural resistance," is the most current key challenge of BIM adoption. For individuals involved in the process of BIM adoption, architects must believe that it can help them to improve their skills for work and to understand and increase their knowledge for efficient sustainable design with BIM. These can only be achieved by executing a successful change of a top-down management strategy for the process and reducing any potential resistance to the change, namely, organizational "culture change" to the resistance. This research's finding agrees with a number of studies on BIM adoption by various professionals, such as architects [22], mechanical contracting SMEs [13], leading construction contractors [17], and owners of large organizations [11]. Son et al. stress that an organizational culture and environment should be created, which is more conducive to BIM implementation in architectural design firm [22], and Poirier et al. [13] add radical change reinforce innovation [13]. Hence, the effective adoption of BIM requires significant changes to the architectural design industry's approach that works at every level and stage of the building lifecycle. Eadie et al. [17] argue that, to overcome the challenges facing the BIM adoption, in addition to solving difficult technical problems, organizations must also solve the softer problems surrounding internal culture change. Cavka et al. [11] further state that significant changes are required in the way of the organizational structure, information representation, and exchange and the way that organizations are planned and implemented, where the changes are both internal and external to the organization, in terms of how the project team generates and exchanges information. These correlate with the research's finding that indicates that the cultural change requires not only that project team members understand that BIM adoption can achieve sustainable design, but also the method for recreating a work flow through implementing BIM, the method to train the members and assign the responsibilities to them, and the method of the change in design management.

However, findings from Chan's study [18] contrast with the research's finding of this paper, which suggests that cultural resistance is an insignificant challenge to the BIM adoption in Hong Kong by assessing challenge in implementing BIM through a questionnaire survey to building designers (i.e., engineer, architect, and landscape architect).

6.2. Top-Down Management Support. One of the main findings in this paper indicates that, with the support of senior management team of the organization, the adoption of BIM can be easy, smooth, and successful, which is in line with the findings of a number of studies [13, 19, 29-31] that stress that the top-down management support is the key to organizational adoption of BIM in construction industry in general $[29,30]$, as architects are encouraged to adopt BIM in their daily practices for learning and practicing. The adoption and implementation of BIM in architectural design project are more about people and process than technology, aligning with results of the studies by Ahuja et al. [19], Poirier et al. [13], and Cheng and Teizer [31], which are obtained, respectively, from team of architects and on-site construction contractors, such as mechanical contractors and construction contractors. However, a study conducted by Ding et al. [21] via questionnaire survey to obtain data 
from architects in Shenzhen city of China finds that the support from the senior management team and the knowledge structure are statistically insignificant for architects' willingness to adopt the BIM. They argued without qualitative evidence that it may be due to the participating architects from architectural design firms that are keen to use new emerging information technology, such as BIM, to obtain business advantage in competition, and architects in Shenzhen, China, are more aware of using of BIM to improve their own capability of competitiveness. The contradiction views may be caused by adopting different research aim, methods, sample, and scale, and the Chinese study focuses on key factors of BIM adoption by using quantitative questionnaire to architects from keen new-emerging-technology architectural design firms in Shenzhen city of China, and this paper aims at investigating relationships between the contextual factors and process for BIM adoption in sustainable design, where rich experience is from top leading architectural design organizations, by employing a mix of quantitative questionnaires followed by qualitative interviews across the UK.

6.3. Current Key Challenges and Drivers. The research extends existing knowledge in a clear view of current key challenges (i.e., insufficient standards and protocols between project players in collaboration, integration, and interoperability, lack of a framework/road-map for outlining the effective strategy and method to implement BIM and train project stakeholders to understand and adopt BIM, overcoming the resistance to change by educating project stakeholders to be aware of potential and value of BIM, and imbalance of adoption and implementation of BIM between project partners and players), and drivers (i.e., client driven, easy and efficient information retrieval for increasing staff production, construction strategy, and project level implementation) for adopting BIM in sustainable building design industry. Poirier et al. [13] point out a similar view on the client driven incentive, and Royal Institution of Chartered Surveyors (RICS) [32] further reinforces the view in line with its survey of BIM adoption. Interestingly, Olatunji's findings [14] via focus group in estimating organizations imply that the level of BIM deployment is still low associated with the low client driven, and it seems that most clients do not worry about the BIM adoption as long as the project meets the current goals.

6.4. Client and Project Managers' Interests. Although client and project manager are ranked as top two key players regarding the BIM adoption in the research conducted by Travaglini et al. [16] via interview from project management point of view. However, the finding of questionnaire in this paper reveals that the project managers' interest on BIM adoption and the different project sizes, respectively, have low positive effect and low negative effect on BIM implementation for sustainable building design projects. This suggests that responding architects use BIM to assist sustainable building design regardless of the project managers' interest or the building project size.
The above mentioned discussions of key research findings clearly indicate that this research contributes the methodology for the investigation of the micro-level BIM adoption in sustainable building design from architects' perspectives. It echoes the of the findings study by Hong et al. [12], where there is a need for examining challenges and overcoming drivers to the challenges, which influence BIM implementation process rather than focusing on the challenges and drivers themselves.

\section{Conclusions}

The limited but growing studies in the field cover micro level BIM adoption and implementation in SMEs architectural company in the UK. However, there is a need for more research studies on investigation and methodologies that explore potential methods to address the micro level BIM adoption challenges aligning its incentive for overcoming during sustainable building design from the UK's leading architectural companies' perspective. Thus, the research in this paper has three key contributions:

(1) To use a robust mixed research method, that is, a questionnaire survey followed by semistructured interviews, to systematically investigate process of implementing micro-level BIM in building design

(2) To focus on development of method and process for BIM implementation concerning factors, that is, the BIM adoption challenges and drivers, rather than the factors themselves

(3) To target sustainable building design at micro level of BIM adoption in architecture firms

For example, the paper presents methods and processes to overcome three key BIM adoption challenges during sustainable building design, such as interoperability, resistance to change, and imbalance of adoption and implementation of BIM between project partners and players, and provides a map of the methods and processes for addressing the key BIM adoption challenges in sustainable building design, as shown in Figure 1, to support architects to implement BIM at the micro level easily and effectively in their sustainable building design projects. Figure 1 is developed as a proposed micro level of BIM adoption framework to address the challenge of the lack of a framework/road-map for outlining the effective strategy and method to implement BIM and train project stakeholders to understand and adopt BIM in sustainable design, which contains a solution for addressing the abovementioned three key BIM adoption challenges by using BIM package and practices for addressing interoperability, as well as implementing culture change, BIM project show case, and regulation and legislation for addressing resistance to change and imbalance of adoption and implementation of BIM between project partners and players. Hence, the proposed micro level of BIM adoption framework is considered highly contextual due to its specificity in industry and discipline. This paper takes steps to develop these contextual factors, that is, BIM 
adoption challenges and drivers, and process to coordinate the adoption and implementation of BIM at micro level.

Although it is difficult to obtain, the paper relies on selfreported data from architects in top leading architectural organizations, that is, large organizations, in the UK. It is worthwhile to further study views of architects in SMEs and the differences between them. However, architects' responses in this paper do not provide an opportunity to test the long-term trends of these hypothetical relationships between the contextual factors and process. Although longitudinal data collection requires significant time and resources, it may be statistically helpful in validating the proposed causal relationship and should therefore continue. Future research that could help with expanding the applicability of the existing proposed framework can collect data in other countries. In addition, future research may consider using observable indicators for measuring the performance of BIM associated methods and processes to improve the robustness of the results. Further, it is necessary to further study other design professionals, such as mechanical designers and service designers, in the same research context. Further study could consider refining the embedded contexts based on the various situations of real practices faced by these design professionals. The methods and processes that enhanced a micro level of BIM adoption framework can be instantly adopted for building design and for architectural companies including SMEs.

\section{Data Availability}

The SPSS data used to support the findings of this study are available from the corresponding author upon request.

\section{Conflicts of Interest}

The authors declare that there are no conflicts of interest regarding the publication of this paper.

\section{Acknowledgments}

The authors would like to thank all the respondents who provided their time and efforts for the research. This research was funded by South China University of Technology Central University Basic Scientific Research Operation Funds (Social Science), South China University of Technology, Guangzhou, China (Grant nos. XYZD201928 and $\mathrm{x} 2 \mathrm{sj} / \mathrm{C} 2191370)$.

\section{References}

[1] S. Azhar, A. Nadeem, J. Y. N. Mok, and B. H. Y. Leung, "Building information modelling (BIM): a new paradigm for visual interactive modeling and simulation for construction projects," in Proceedings of the First International Conference on Construction in Developing Countries, pp. 435-446, Karachi, Pakistan, August 2008.

[2] C. Eastman, P. Teicholz, R. Sacks, and K. Liston, BIM Handbook: A Guide to Building Information Modeling for Owners, Managers, Designers, Engineers and Contractors, Wiley, New York, NY, USA, 2008.
[3] Government Construction Strategy, 2011, https://www.gov. uk/government/uploads/system/uploads/attachment_data/ file/61152/Government-Construction-Strategy_0.pdf.

[4] Construction 2025: Industrial Strategy: Government and Industry in Partnership, 2013, https://www.gov.uk/ government/uploads/system/uploads/attachment_data/file/ 210099/bis-13-955-construction-2025-industrial-strategy. pdf.

[5] RIBA Plan of Work, 2013, https://www.ribaplanofwork.com/.

[6] P. Coates, Y. Arayici, L. Koskela et al., "The key performance indicators of the BIM implementation process," in Proceedings of the ICCBE Conference, Nottingham, UK, June 2010.

[7] S. Mihindu and Y. Arayici, "Digital construction through BIM systems will drive the re-engineering of construction business practices," in Proceedings of the International Conference Visualisation, IEEE Computer Society, Los Alamitos, CA, USA, July 2008.

[8] Z. Liu, M. Osmani, P. Demian, and A. Baldwin, "A BIM-aided construction waste minimisation framework," Automation in Construction, vol. 59, pp. 1-23, 2015.

[9] B. Succar and M. Kassem, "Macro-BIM adoption: conceptual structures," Automation in Construction, vol. 57, pp. 64-79, 2015.

[10] M. Kassem and B. Succar, "Macro BIM adoption: comparative market analysis," Automation in Construction, vol. 81, pp. 286-299, 2017.

[11] H. Cavka, S. Staub-French, and R. Pottinger, "Evaluating the alignment of organizational and project contexts for BIM adoption: a case study of a large owner organization," Buildings, vol. 5, no. 4, pp. 1265-1300, 2015.

[12] Y. Hong, S. M. Sepasgozar, A. F. F. Ahmadian, and A. Akbarnezhad, "Factors influencing BIM adoption in small and medium sized construction organizations," in Proceedings of the International Symposium on Automation and Robotics in Construction, vol. 34, Vilnius Gediminas Technical University, Vilnius, Lithuania, pp. 1-7, July 2016.

[13] E. Poirier, S. Staub-French, and D. Forgues, "Embedded contexts of innovation," Construction Innovation, vol. 15, no. 1, pp. 42-65, 2015.

[14] O. Olatunji, "Modelling organizations' structural adjustment to BIM adoption: a pilot study on estimating organisations," Electronic Journal of Information Technology in Construction, vol. 16, pp. 652-668, 2011.

[15] U. Gurevich, R. Sacks, and P. Shrestha, "BIM adoption by public facility agencies: impacts on occupant value," Building Research \& Information, vol. 45, no. 6, pp. 610-630, 2017.

[16] A. Travaglini, M. Radujković, and M. Mancini, "Building information modelling (BIM) and project management: a stakeholders perspective," Organization, Technology \& Management in Construction: An International Journal, vol. 6, no. 2, pp. 1001-1008, 2014.

[17] R. Eadie, H. Odeyinka, M. Browne, C. McKeown, and M. Yohanis, "Building information modelling adoption: an analysis of the barriers to implementation," Journal of Engineering and Architecture, vol. 2, no. 1, pp. 77-101, 2014.

[18] C. T. Chan, "Barriers of implementing BIM in construction industry from the designers' perspective: a Hong Kong experience," Journal of System and Management Sciences, vol. 4, no. 2, pp. 24-40, 2014.

[19] R. Ahuja, M. Jain, A. Sawhney, and M. Arif, “Adoption of BIM by architectural firms in India: technology-organization-environment perspective," Architectural Engineering and Design Management, vol. 12, no. 4, pp. 311-330, 2016. 
[20] Y. Arayici, P. Coates, L. Koskela, M. Kagioglou, C. Usher, and K. O'Reilly, "BIM adoption and implementation for architectural practices," Structural Survey, vol. 29, no. 1, pp. 7-25, 2011.

[21] Z. Ding, J. Zuo, J. Wu, and J. Wang, "Key factors for the BIM adoption by architects: a China study," Engineering, Construction and Architectural Management, vol. 22, no. 6, pp. 732-748, 2015.

[22] H. Son, S. Lee, and C. Kim, "What drives the adoption of building information modeling in design organizations? An empirical investigation of the antecedents affecting architects' behavioral intentions," Automation in Construction, vol. 49, pp. 92-99, 2015.

[23] A. Ghaffarianhoseini, J. Tookey, A. Ghaffarianhoseini et al., "Building information modelling (BIM) uptake: clear benefits, understanding its implementation, risks and challenges," Renewable and Sustainable Energy Reviews, vol. 75, pp. 1046-1053, 2017.

[24] K. Ku and M. Taiebat, "BIM experiences and expectations: the constructors' perspective," International Journal of Construction Education and Research, vol. 7, no. 3, pp. 7-25, 2011.

[25] NBS National BIM Report, 2012, https://www.thenbs.com/ knowledge/nbs-national-bim-report-2012.

[26] National BIM Report 2016, 2016, https://www.thenbs.com/ knowledge/national-bim-report-2016.

[27] NBS National BIM Report 2011, 2011, https://www.thenbs. com/knowledge/nbs-national-bim-report-2011.

[28] D. B. Arensman and M. E. Ozbek, "Building information modeling and potential legal issues," International Journal of Construction Education and Research, vol. 8, no. 2, pp. 146156, 2012.

[29] N. Gu and K. London, "Understanding and facilitating BIM adoption in the AEC industry," Automation in Construction, vol. 19, no. 8, pp. 988-999, 2010.

[30] H. Xu, J. Feng, and S. Li, "Users-orientated evaluation of building information model in the Chinese construction industry," Automation in Construction, vol. 39, pp. 32-46, 2014.

[31] T. Cheng and J. Teizer, "Real-time resource location data collection and visualization technology for construction safety and activity monitoring applications," Automation in Construction, vol. 34, pp. 3-15, 2013.

[32] Survey Finds Lack of Client Demand is Biggest Barrier to BIM, 2013, http://www.inbuilding.org/b/architecture-news/ archive/2013/05/10/survey-finds-lack-of-client-demand-isbiggest-barrier-to-bim.aspx. 